north by anyone else. Quitta is situated $5^{\circ} \mathrm{N}$. latitude, and $\mathrm{I}^{\circ}$ E. longitude. WAlter Higginson

Quitta, West Coast Africa, September 25 B. ManNing

\section{Two Kinds of Stamens with Different Functions in the same Flower}

IT may be worth mentioning that cases strongly analogous to those described in NATURE (vol. xxiv. p. 307, and vol. xxvi. p. 386, are also to be observed among the Monocotyledons in the family of Commelynacex, an 1 that these cases offer some graduations.

In Tradescantia virginica, L., the flowers, as is generally known, are turned upwards and quite regular, the leafy organs of each whorl ( 3 sepals, 3 petals, 3 outer, 3 inner stamens, 3 united carpels) being alike and equal in size. As Delpino has clearly shown (Ulteriori osservazioni, parte ii. fascic. 2, p. 297) these flowers are adapted to Apidæ, which in order to collect pollen take hold of the articulated hairs of the filaments. In some other species here to be considered the adaptation to pollencollecting bees has remained, but the flowers have turned laterally, and thus not only has their form become irregular (bi-laterally symmetrical or zygomorphous), but also the function of the stamens has gradually changed.

In Tinnantia undata, Schlecht. (Fig. 1), sepals and petals are still almost unaltered in form and size, only stamens and pistil have become markedly irregular. The broad roundi.h petals, which are light purple, spread in a perpendicular plane. The 3 upper stamens, with shorter filaments projecting from

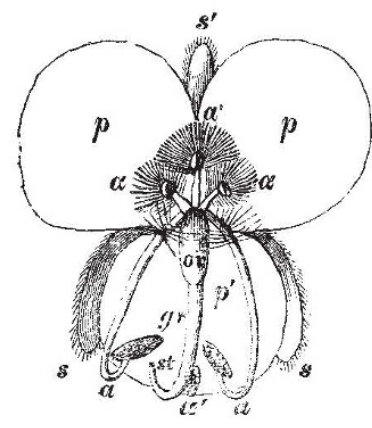

FIG. I.

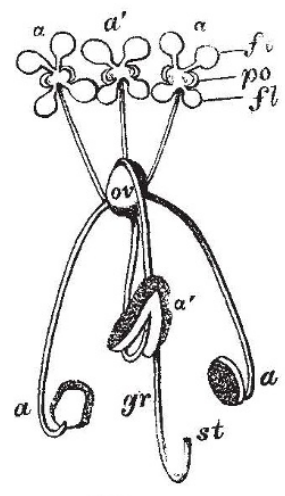

FIG. 2.
F1G. x.-Front view of the flower of Tinnantia undata, Schlecht. FiG. 2.Front view of the androceum and gynæcium of Commelyna calestis, Willd. $s, s, s^{\prime}$, sepals; $p, p, p^{\prime}$ petals ; $a, a, a^{\prime}$, outer whorl of anthers $a, a, a^{\prime}$, inner whorl of anthers, or ovary ; $g r$, style ("Gr.ffel"); st,
stigma.

the middle of the flower, are highly conspicuous by a diverging tuft of bright yellow articulated hairs, which on the last third of the light-purple filaments surround the golden yellow anthers like a cone of golden rays. At the tips of these filaments golden yellow pollen-grains are presented by the whole front side of the three upper anthers.

The three lower stamens are much longer, directed obliquely downwards and forwards, with only their tips bending upwards, a little overtopped by the pistil, which has the same direction and incurvation. These parts, like the same parts in the described Melastomaceæ, will hardly be perceived by an advancing insect, "owing to their projection against the broad-petalled corolla of the same colour in the background," for not only the style and the filaments, but also the hairs on the base on the two lateral lower filaments are of the same purple colour as the petals, and even the bluish lower anthers with their yellowish pollen are but feebly conspicuous. Any one of the Apidæ or Syrphidæ of suitable size, however, when making for the upper yellow stamens in order to collect their pollen ( $I$ have only once observed the honey-bee doing so), will involuntarily repose on the projecting parts, and at first bring the stigma and then the two lateral of the lower anthers into contact with the under-side of its abdomen, and thus regularly effect cross fertilisation.

Here, then, as in Heeria, \&c., the anthers have differentiated into upper ones, which attract insects and afford food to them, and lower ones which attach their pollen to the visitors, and cause it to be transported by them to the stigma of the next visited flowers. Also differentiation in the pollen of the two kinds of anthers in our Tinnantia has begun to take place, but contrary to Melastoma, the pollen-grains of the short stamens here are smaller than those of the longer ones. I measured. numerous pollen-grains of two individuals in a moistened state (where they are of elliptical form), and found in the one stem the pollen-grains of the short stamens (in I-1000 m.m.) 62-75 long, 3I-38 broad, those of the longer ones 68-94 long, 38.44 broad; in the other stem, those of the short stamens $53-69$ long, 28-37 broad; those of the longer ones 59-78 long, 31-40 broad. Both kinds of pollen proved to be quite fertile.

Commelyna coelestis, Willd. (Fig. 2) possesses in general the same contrivances for cross-fertilisation, but has gone a step further in differentiation. Its upper sepal is plainly smaller, its lower petal plainly larger than the two other ones; its upper anthers $\left(\alpha, a^{\prime} \alpha\right)$ have differentiated in themselves; two small lateral portions of each of them $(p o)$ produce a little pollen and four cross-like diverging flaps $(f)$, which are much larger, aitract insects by their bright yellow colour strikingly contrasting with the azure corolla, and perhaps at the same time serve as food to the visitors. The articulated hairs of the filaments thus having lost not only their original function (which they have in all stamens of Tradescantia) as supports for the feet of pollencollecting bees, but also their secondary function (which they have in the upper stamens of Tinnantia) of attracting insects, have disappeared altogether. The middlemost of the lower anthers, which in Tinnantia is nearly useless from its position behind the style here, has erected and become much larger than the two lateral ones, so as to be eminently useful.

The pollen-production of the upper anthers appears to be vanishing, not only from the diminution of the quantity of produced pollen, but also from the great variability of the size of the pollen grains. For whilst the pollen grains of the two lateral lower anthers only differ in length from 75 to 90 , in breadth from 45 to 68 , and those of the middlemost lower anther in length from $5^{6}$ to 82 , in breadth from 37 to 56 , those of the three upper anthers fluctuate from 50 to 87 length, and from 3 I to 56 breadth.

In Cummelyna communis, differentiation has gone still further ; the upper sepal and the lower petal are relatively very small; the upper filaments, like the upper petals, are blue-coloured; the lower filament, like the pistil and the lower petal, are colourless. The upper anthers, as far as I have seen (without microscope) produce no more pollen

The examination of other species and genera of Commelynacer probably would show a longer scale of gradations.

Lippstadt, October 25

HermanN MÜLLER

\section{A Curious Halo}

There appeared in NATURe, vol. xxvi. pp. 268, 293, two articles headed "A Curious Halo," which reminded me of an analogous and still more curious phenomenon occurring sometimes here in China, during the hot season. I beg to hand you a few lines on that subject, from the Monthly Bulletin of the Zi-ka-wei Observatory for August, I877 :-

"A phenomenon to which $I$ wish to call the attention of meteorologists was observed many times during that month (August), as also in July. It does not seem to take place in Europe, and I am inclined to think that it cannot occur except with an atmosphere over-charged with aqueous vapour, as it is the case with us in July and August. In the evening, just after sunset, or in the morning even long before sunrise, no matter what the direction of the wind and the barometric pressure may be, provided the day or night were very warm, bands of a tint varying from the faintest to the deepest blue are seen to appear upon the whitish or roseate vault of heaven. They usually are first seen in the east at evening and in the west at morning time, seemingly radiating from a common centre diametrically opposite the sun's position. At other times they emerge from the very position of the sun, or from both points at once, the interval being either free from bands or completely encircled by them.

"Last year (1876), on the morning of September 4, I en. joyed a most interesting sight. It was about $5 \mathrm{a.m}$., the moon, then on her nineteenth day, was above the western horizon, and ju:t being partially eclipsed; now from her bright disc, as from a radiating centre, shot out a number of those bands or blue beams; they traversed the whole expanse of the sky, and seemed to converge towards a point whose situation in the east 